Toklu et al. HCA Healthcare Journal of Medicine (2020) 1:1

https://doi.org/10.36518/2689-0216.1046

\title{
Editorial
}

\section{A New Journal to Publish Houses of Bricks: Introducing the HCA Healthcare Journal of Medicine}

Hale Z. Toklu, PhD, MPharm, ${ }^{1,2}$ Bruce Deighton, PhD, ${ }^{2}$ Graig Donini ${ }^{2}$

\section{Abstract}

Author affiliations are listed at the end of this article.

Correspondence to: Hale Z. Toklu, PhD, MPharm North Florida Regional Medical Center GME Bldg, Suite 122 E 1147 NW 64th Terrace Gainesville, FL 32605 (Hale.Toklu@hcahealthcare. com)

\section{Keywords}

journal; medical education; HCA Healthcare; peer review, research; scholarly communication, open access publishing; education, medical, graduate

"Publish houses of brick, not mansions of straw." Dr. William G. Kaelin Jr., 2019's Nobel Laureate for Physiology or Medicine and Professor of Medicine at Harvard University and the Dana-Farber Cancer Institute, wrote this directive to researchers in his 2017 article in Nature. With the advancement in biomedical sciences and internet technologies, publishing has become much easier in comparison to the past. The publication period is shorter and dissemination is broader. However, as Dr. Kaelin emphasized in his article, too many published results are true only under narrow conditions, or cannot be reproduced at all. These 'mansions of straw' limit our ability to effectively judge which results are credible and worthy of adoption when caring for our patients, but also risk painting medical science in a negative light with our patients and the public in general. Therefore, it becomes even more important to publish "houses of brick."

The HCA Healthcare Journal of Medicine is a new peer-reviewed, scientific periodical dedicated to the care and improvement of human life by publishing and disseminating scholarly work focusing on innovation and enhanced quality, developing new knowledge in clinical care, and contributing to research in medical education. With $250+$ residency and fellowship programs, HCA Healthcare Graduate Medical Education is committed to providing residents and fellows opportunities to learn and grow, this includes support for scholarly activities and the chance to immerse themselves into and be challenged by the academic side of medicine in a patient-centered, constantly evolving and improving environment. More than 2,300 scholarly activities were completed last year by HCA Healthcare faculty, residents and fellows, which includes journal publications and conference presentations. Some of this year's output graces the pages of this first issue. But this journal isn't just about sharing the pursuits of HCA Healthcare Graduate Medical Education, we also share the quality work of faculty, physicians, and others doing medical research and clinical practice at HCA Healthcare facilities and beyond. While we have great pride in the work being done at HCA Healthcare, this is not an internal journal, we are asking for "bricks" from all over the world to build "houses" for global healthcare.

The Journal is open access and has no subscription or author fees. HCA Healthcare and our Graduate Medical Education team wanted to provide this space to encourage physicians, no

\section{HCA in Healthcare}

www.hcahealthcarejournal.com

(c) 2020 HCA Physician Services, Inc. d/b/a Emerald Medical Education
HCA Healthcare Journal of Medicine 
matter the stage of their career, to write and publish their work without any financial barriers to entry. Each article will be judged on its own merits and published articles will be freely available to all readers. We want to provide significant and innovative articles to help advance the practice of medicine. It is a vital part of our mission to not only provide the best care possible to our patients today, but to focus on how we can improve that experience tomorrow.

Each issue will be divided into five sections: Editorial and News, Education, Clinical Review, Research and Humanities. The journal's scope is broad which reflects our roots in graduate medical education. We want the journal to showcase not only original research but also clinically-relevant topics to aid our understanding of disease, educational content to continue the growth of physicians from medical school to continuing medical education, and reveal the human side of practice through artistic and narrative outlets.

This issue features an interesting review and discussion about starting a medical school in Southeast Florida. The Nova Southeastern University Dr. Kiran C. Patel College of Allopathic Medicine is one of several new medical schools to open their doors this past decade. HCA Healthcare is the primary clinical affiliation for this new school, including construction of a new teaching hospital on the Nova Southeastern University campus in Ft. Lauderdale. This thoughtful piece shares strategies and insight on building a medical school that we hope will benefit other recently established schools, and others who may be in the process of developing a new medical school in the future.

The research section has an encouraging article that looks at the gender of chief residents in Emergency Medicine programs. The research didn't discover any disparity in the gender representation of EM chief residents in the surveyed facilities. The glass ceiling has been showing cracks in the medical field and this research gives us hope that the trend will result in full gender equity in the near future.

It has been gratifying to see the generosity of our colleagues who have submitted their works to a new journal or have helped with reviewing the contents. We also want to thank our Editorial Board for their hard work in establishing the journal. We are still finding our way, but we hope the journal will become "must read" content in the months and years ahead, for the quality of our published research and our spirit of giving and humanity to try and improve the conditions of our patients, ourselves and our communities.

\section{Conflicts of Interest}

The authors declare they have no conflicts of interest.

Dr. Hale Toklu, Dr. Bruce Deighton and Graig Donini are employees of HCA Healthcare Gradvate Medical Education, a company affiliated with the journal's publisher.

This research was supported (in whole or in part) by HCA Healthcare and/or an HCA Healthcare affiliated entity. The views expressed in this publication represent those of the author(s) and do not necessarily represent the official views of HCA Healthcare or any of its affiliated entities.

\section{Author Affiliations}

1. Pharmacology and Medical Education, University of Central Florida College of Medicine, Department of Clinical Sciences

2. HCA Healthcare Graduate Medical Eduction

\section{References}

1. Kaelin Jr, WG (2017) Publish houses of brick, not mansions of straw. Nature. 2017;(545):387-387. https://doi.org/10.1038/545387a 